\title{
Endogenous Histamine Facilitates Long-Term Potentiation in the Hippocampus during Walking
}

\author{
Tao Luo ${ }^{1}$ and L. Stan Leung ${ }^{1,2}$ \\ ${ }^{1}$ Department of Physiology and Pharmacology and ${ }^{2}$ Neuroscience Program, University of Western Ontario, London, Ontario, Canada N6A 5C1
}

\begin{abstract}
Long-term potentiation (LTP) in hippocampal CA1 depends on the behavioral state of LTP induction. We hypothesize that histaminergic activity in the septohippocampal system, which is active during walking compared with other behavioral states, is responsible for the behavioral dependence of LTP. Field basal-dendritic EPSPs of CA1 pyramidal cells were recorded in freely behaving rats, and LTP was induced by a single $200 \mathrm{~Hz}$ stimulation train ( $0.5 \mathrm{~s}$ duration). Basal-dendritic LTP was facilitated when induced during walking compared with awake immobility (IMM) or rapid-eye-movement sleep. The facilitation of basal-dendritic LTP during walking was abolished by lesion of tuberomammillary nucleus (TMN) neurons with orexin-saporin or by intramedial-septal infusion of the $\mathrm{H}_{1}$ histaminergic blocker triprolidine but not the $\mathrm{H}_{2}$ histaminergic blocker cimetidine. Conversely, histamine infusion in the medial septum enhanced the basal-dendritic LTP induced during IMM to a magnitude similar to that induced during walking. Basal-dendritic LTP induced during walking was not further enhanced by intraseptal histamine infusion. Combined with the previous result that behavior-dependent LTP is mediated by cholinergic septohippocampal neurons, we conclude that the facilitation of basal-dendritic LTP in CA1 during walking was mediated by TMN histaminergic afferents acting on $\mathrm{H}_{1}$ receptors in the medial septum, which may then enhance cholinergic and noncholinergic inputs to the hippocampus.
\end{abstract}

\section{Introduction}

Histamine is a neurotransmitter that is synthesized by neurons in the tuberomammillary nucleus (TMN) of the posterior hypothalamus (Sherin et al., 1998). Histamine-containing nerve fibers project to many structures in the brain, among them the medial septum and the hippocampus (Panula et al., 1989). Histaminergic circuits in the brain regulate numerous physiological functions and behaviors, including sleep-wake activities, circadian and feeding rhythms, learning, and memory (Doi et al., 1994; Inoue et al., 1996; Parmentier et al., 2002; Dere et al., 2003; Haas and Panula, 2003; Haas et al., 2008). Histamine has been shown to facilitate synaptic plasticity in hippocampal slices in vitro (Brown et al., 1995), perhaps in part by enhancing NMDA receptor currents (Bekkers, 1993; Vorobjev et al., 1993). However, a physiological action of endogenously released histamine in modulating synaptic plasticity in vivo has not been shown.

Synaptic plasticity, in particular long-term potentiation (LTP), is widely regarded as the cellular basis of learning and memory (Martin et al., 2000; Neves et al., 2008). Our laboratory reported that LTP at the basal dendrites of hippocampal CA1 area was NMDA receptor dependent (Leung and Shen, 1993, 1999), and it was enhanced if induction occurred during walking compared with during awake immobility (IMM), rapid-eyemovement sleep (REMS), or slow-wave sleep (SWS) (Leung et al., 2003). The walking-facilitated LTP required intact septohip-

Received March 1, 2010; revised March 30, 2010; accepted April 20, 2010.

This research was supported by Canadian Institutes of Health Research Grant MOP-15685.

Correspondence should be addressed to Dr. L. Stan Leung, Department of Physiology and Pharmacology, The University of Western Ontario, London, Ontario, Canada N6A 5C1. E-mail: sleung@uwo.ca.

DOI:10.1523/JNEUROSCI.1127-10.2010

Copyright $\odot 2010$ the authors $\quad 0270-6474 / 10 / 307845-08 \$ 15.00 / 0$ pocampal cholinergic neurons and $\mathrm{M}_{1}$ muscarinic receptors (Leung et al., 2003; Doralp and Leung, 2008). The participation of septohippocampal GABAergic and glutamatergic neurons (Brashear et al., 1986; Sotty et al., 2003; Colom et al., 2005) in hippocampal LTP is not known.

A high release of acetylcholine (ACh) during walking compared with IMM (Dudar et al., 1979) may account for the difference in LTP induced during walking and IMM. Cholinergic activity alone, however, cannot explain the facilitation of LTP during walking compared with REMS, because ACh release in the hippocampus was reported to be the same or higher during REMS compared with active waking (Marrosu et al., 1995), corroborated by the firing rate of identified cholinergic basal forebrain neurons (Lee et al., 2005). Because neurons containing norepinephrine, serotonin, or histamine fire actively during active waking but not during REMS (Aston-Jones and Bloom, 1981; Fornal et al., 1985; Takahashi et al., 2006), these monoaminergic neurons may facilitate LTP during walking compared with REMS.

In the present study, we hypothesize that TMN histaminergic neurons facilitate LTP during walking compared with REMS or IMM. TMN histaminergic neurons were silent during SWS and REMS, fired moderately during quiet awake, and typically fired maximally during active waking with "motor activities" or with "a high level of vigilance" (Takahashi et al., 2006). In the first experiment, we showed that lesion of TMN neurons by orexinsaporin abolished the facilitation of basal-dendritic LTP in CA1 during walking compared with during REMS. In the second experiment, we showed that an $\mathrm{H}_{1}$, but not $\mathrm{H}_{2}$, histaminergic receptor antagonist infused in the medial septum blocked the LTP facilitation during walking. In the third experiment, we showed 
that histamine infusion in the medial septum enhanced basaldendritic LTP during IMM but not during walking.

\section{Materials and Methods}

Animals. Experiments were performed on adult male Long-Evans rats (235-280 g; Charles River Canada). All animals were given water and regular rat chow ad libitum and housed under climate-controlled conditions with a $12 \mathrm{~h}$ light/dark cycle (lights on at 7:00 A.M.). All procedures were approved by the local Animal Use Committee and conducted according to the guidelines of the Canadian Council for Animal Care.

Electrodes and cannula implantation. The animals were anesthetized with sodium pentobarbital $60 \mathrm{mg} / \mathrm{kg}$ intraperitoneally and implanted bilaterally with electrodes in the dorsal hippocampus as described previously (Leung and Shen, 1999; Leung et al., 2003). Each electrode was a stainless-steel $125-\mu \mathrm{m}$-diameter wire insulated with Teflon except at the cut tip. A pair of recording electrodes was implanted to straddle the cell layer of CA1, at $4.6 \mathrm{~mm}$ posterior to bregma (P) and $2.8 \mathrm{~mm}$ lateral to midline (L). The dorsal electrode was typically in CA1 stratum oriens or alveus, and the ventral electrode was in CA1 stratum radiatum. Stimulating electrodes were placed on the same side anterior to the recording electrodes (in mm: P3.2 and L1.7) or homotopically on the opposite side. Two screws inserted into the skull over the frontal cortex and cerebellum served as the stimulus anode and the recording ground, respectively. Evoked potentials were monitored to optimize the placement of electrodes during surgery.

In some experiments, rats were implanted with a single guide cannula above the medial septum [coordinates in $\mathrm{mm}$ : anterior to bregma 1.0 and L0). The guide cannula was a 23 gauge (external diameter) stainless-steel tubing cut to a length of $18.5 \mathrm{~mm}$. At the time of infusion, an inner cannula of 30 gauge was lowered through the guide cannula into the medial septum. The following drugs were used: histamine (H7125; Sigma), cimetidine (C4522; Sigma), and triprolidine (T6764; Sigma). Histamine and triprolidine were dissolved in $0.9 \%$ physiological saline solution, and cimetidine was dissolved in $0.15 \mathrm{~m}$ hydrochloric acid with saline and then adjusted to neutral $\mathrm{pH}$ with $1 \mathrm{~m}$ sodium hydroxide. Each drug or saline of $0.5 \mu \mathrm{l}$ volume was infused into the medial septum at a rate of $\sim 0.5 \mu \mathrm{l} / \mathrm{min}$ using a Hamilton syringe. Histamine was administered in a concentration of $100 \mu \mathrm{M}$, which was found to evoke electrophysiological and neurochemical responses in vivo and in vitro (Bacciottini et al., 2002; Xu et al., 2004; Kuo and Dringenberg, 2008). The concentration of triprolidine $(0.5 \mu \mathrm{M})$ and cimetidine $(100 \mu \mathrm{M})$ were reported to block the histamine responses as reported previously (Cecchi et al., 2001; Bacciottini et al., 2002; Xu et al., 2004).

TMN lesion. TMN neurons were lesioned using orexin- 2 conjugated to saporin (orexin-saporin) that binds to the orexin-2 receptors on the TMN neurons (Eriksson et al., 2001), as was done in previous studies (Gerashchenko et al., 2004; Blanco-Centurion et al., 2007). Briefly, animals were anesthetized and secured in a stereotaxic frame. After a small hole was drilled in the skull over the TMN, the dura was incised, a 30gauge stainless-steel cannula was stereotaxically lowered into the TMN (coordinates in mm: P4.2, $\mathrm{L} \pm 1.0$, and 9.6 ventral to the skull surface), and $250 \mathrm{nl}$ of orexin-saporin ( $250 \mathrm{ng} / \mu \mathrm{l}$; Advanced Targeting Systems) was infused over 2 min using a Hamilton syringe driven by a infusion pump. After infusion, the cannula was left in place for $10 \mathrm{~min}$ and then withdrawn slowly. In sham lesioned control rats, the infusion cannula was simply lowered and left in place for $10 \mathrm{~min}$.

Electrophysiology. Two weeks after surgery, the animals were habituated to the recording environment for $1-2 \mathrm{~d}$. Recording was performed between 9:00 A.M. and 7:00 P.M. Photoisolated current stimulus pulses ( $0.2 \mathrm{~ms}$ duration) were delivered cathodally to one stimulating electrode, using a screw in the skull as the anode. Monopolar recordings were made, with a skull screw serving as both the reference and the ground. Based on the electrophysiological response, a stimulus electrode that evoked basaldendritic field EPSPs (fEPSPs) in CA1 was selected, and evoked potentials were recorded from another pair of electrodes, ipsilateral or contralateral to the stimulating electrode. Subsequent histology confirmed that the stimulating electrode was located at CA1 stratum oriens or alveus. Two channels of evoked responses were filtered at $0.1 \mathrm{~Hz}$ to 3
$\mathrm{kHz}$ and sampled at $7 \mathrm{kHz}$, and average evoked potentials (AEPs) (eight sweeps) were acquired online by a custom microcomputer program.

Baseline AEPs were recorded for $1-1.5 \mathrm{~h}$ before the induction of LTP. All AEPs were recorded during IMM, but LTP was induced during IMM, walking, or REMS. A high-frequency stimulus train (tetanus) was used for LTP induction; the train consisted of 100 pulses at $200 \mathrm{~Hz}(5 \mathrm{~ms}$ interpulse interval), at a stimulus intensity of $0.8-1.5 \times$ the $f E P S P$ threshold. The tetanic stimulus intensity was typically low enough so that an afterdischarge $(\mathrm{AD})$ was not evoked. However, a few experiments in which a short $(<15 \mathrm{~s})$ AD was evoked were included, because the LTP magnitudes were comparable with experiments that evoked no AD (Leung and Shen, 1993). AEPs were recorded at "fixed" times of 5, 10, 15, $20,30,60,90,120,150$, and $180 \mathrm{~min}$ after the tetanus. Previous data showed that the magnitude of LTP was not significantly different among test pulses of 1.5-2 $\times$ fEPSP threshold (Leung and Shen, 1995); therefore, AEPs were recorded with test pulses of $1.5 \times$ threshold intensity. During baseline and at 1 and $2 \mathrm{~h}$ after tetanus, four different stimulus intensities $(1 \times, 1.2 \times, 2 \times$, and $4 \times$ fEPSP threshold) were used to generate inputoutput curves. The maximal slope of the fEPSP during the falling or rising phase (over $2 \mathrm{~ms}$ interval) was measured from the AEPs. The last six recordings before the tetanus were averaged to determine the baseline value, which was normalized to unity, or $100 \%$. For each experiment, the response after tetanus was normalized by the baseline average.

Hippocampal EEG during walking and IMM was recorded before and after saline and at 7-10 min after histamine, triprolidine, cimetidine, or septal infusion into the medial septum but before tetanic stimulation. Because the time window was brief, not all rats could be recorded in both IMM and walking after septal infusion. EEG was effectively sampled at $200 \mathrm{~Hz}$ (after averaging five consecutive samples digitized at $1 \mathrm{kHz}$ ) with 3 and $10 \mathrm{~dB}$ attenuation points at 84 and $180 \mathrm{~Hz}$, respectively. A power spectrum was obtained from at least two segments, each of 1024 points (or $5.12 \mathrm{~s}$ duration), of artifact-free EEG. After smoothing and averaging, spectral estimates had $0.195 \mathrm{~Hz}$ resolution, $2.15 \mathrm{~Hz}$ bandwidth (interval of smoothing), and $>20$ degrees of freedom (Leung, 1985).

Experimental design. In the first experiment, animals were given TMN lesion or sham operation. Tetanic stimulation was delivered during two behavioral states, at 15-28 d after TMN or sham lesion: (1) walking, when the rat was walking on a horizontal surface and hippocampal EEG showed a regular theta rhythm; (2) REMS, when the rat was immobile in a sleep posture and accompanied by a regular hippocampal theta rhythm. Repeated experiments on one rat were conducted with an interval of $>5$ $\mathrm{d}$, and LTP was induced during walking and REMS in a random order.

In the second experiment, animals received intraseptal infusions of triprolidine $\left(0.5 \mu \mathrm{M}\right.$ in $0.5 \mu \mathrm{l}$, a selective $\mathrm{H}_{1}$ receptor antagonist) or cimetidine ( $100 \mu \mathrm{M}$ in $0.5 \mu \mathrm{l}$, a selective $\mathrm{H}_{2}$ receptor antagonist) $10 \mathrm{~min}$ before a tetanus was delivered during walking. Control experiments used intraseptal infusion of $0.5 \mu \mathrm{l}$ of saline, $10 \mathrm{~min}$ before the tetanus during walking. In the third experiment, animals received intraseptal infusions of histamine ( $100 \mu \mathrm{M}$ in $0.5 \mu \mathrm{l})$ or saline $(0.5 \mu \mathrm{l}) 10 \mathrm{~min}$ before a tetanus was delivered during IMM, i.e., when the rat held its head up against gravity, with eyes open and no gross body movements. In a separate group of rats, tetanus was delivered during walking $10 \mathrm{~min}$ after intraseptal infusion of either histamine $(0.5 \mu \mathrm{l}$ of $100 \mu \mathrm{M})$ or saline $(0.5 \mu \mathrm{l})$. Each rat was used in paired drug (triprolidine, cimetidine, or histamine) and saline experiments, in a random order with a minimum of $5 \mathrm{~d}$ between experiments.

Immunohistochemistry and histology. At the end of experiment, animals were anesthetized with pentobarbital and perfused with PBS, followed by $4 \%$ paraformaldehyde at $\mathrm{pH}$ 7.4. The brain was removed and postfixed in $4 \%$ paraformaldehyde overnight at $4^{\circ} \mathrm{C}$ and then dehydrated in $0.1 \mathrm{M}$ PBS containing $18 \%$ sucrose at $4^{\circ} \mathrm{C}$. Blocks containing the hypothalamus were cut on a freezing microtome into $40-\mu \mathrm{m}$-thick coronal sections. Adenosine deaminase (ADA) expression was detected as described previously using a routine avidin-biotin complex immunohistochemistry method (Blanco-Centurion et al., 2007). Nearly all ADA-immunoreactive neurons in the hypothalamus, except for small cells lateral to the posterior arcuate nucleus, were also immunoreactive for histidine decarboxylase, the synthesizing enzyme for histamine (Senba et al., 1985). Briefly, the tissue sections were incubated with the primary antibody against ADA 
A

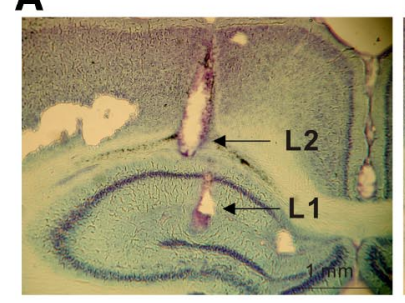

D

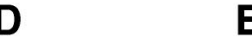

E
B

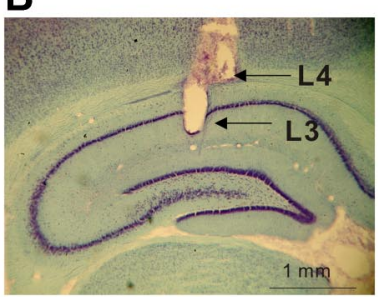

$\mathbf{F}$

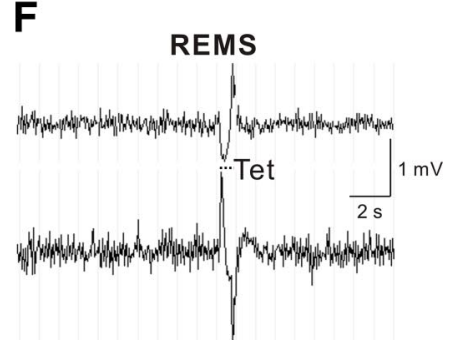

Figure 1. Recording of hippocampal basal-dendritic evoked potentials in CA1 and intraseptal cannula. $\boldsymbol{A}-\boldsymbol{C}$, Representative coronal sections showing locations of electrodes and cannula. $\boldsymbol{A}$, Anterior pair of hippocampal electrodes, L1 and L2 at P3.2, L1.7; $\boldsymbol{B}$, the posterior electrode pair L3 and L4 at P4.6, L2.8. C, Section showing a cannula track through the medial septum, with arrow indicating the end of the track. $\boldsymbol{D}$, Representative basal-dendritic average fEPSPs evoked by cathodal stimulation of $L 2$ and recorded with reversed polarity across $L 3$ and $L 4$ electrodes; shock artifacts are labeled by filled dots. $\boldsymbol{E}, \boldsymbol{F}, \mathrm{EEG}$ from $\mathrm{L} 3$ and $L 4$ electrodes recorded around the time of application of the high-frequency stimulus train [tetanus (Tet)] for inducing LTP, during walking $(\boldsymbol{E})$ and REMS $(\boldsymbol{F})$; a theta rhythm accompanied both walking and REMS.
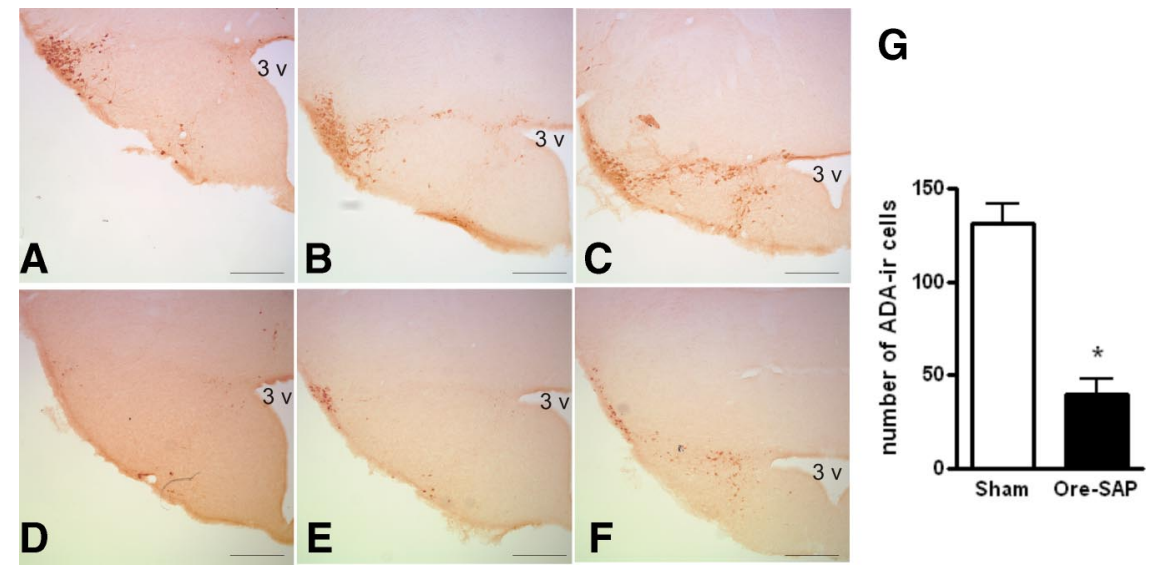

Figure 2. ADA-immunoreactive (ADA-ir) neurons in the TMN in representative orexin-saporin (Ore-SAP) lesion and sham lesion rats. Coronal section through the TMN of sham lesion rats $(\boldsymbol{A}-\boldsymbol{C})$ and lesion rats with orexin-saporin infusion into the TMN $(\boldsymbol{D}-\boldsymbol{F}) .3 \mathrm{~V}$, Third ventricle. Scale bar, $0.25 \mathrm{~mm}$. G, Number of ADA-immunoreactive neurons in sections through the TMN was significantly decreased $\left({ }^{*} p<0.0001\right.$, Student's $t$ test) in orexin-saporin-treated rat $(n=9)$ compared with sham lesion rats $(n=8)$.

dent's $t$ test. Statistical analysis for the normalized fEPSP slope at fixed times after the tetanus were subjected to a two-factor (group $\times$ time) repeated-measures ANOVA, followed by post hoc Bonferroni's test. $p<0.05$ was considered to be significant.

\section{Results}

Ipsilateral or contralateral stimulation of CA1 stratum oriens (L2 electrode in Fig. $1 A$ ) evoked a negative fEPSP at the surface electrode in CA1 (stratum oriens) and a positive fEPSP at the stratum radiatum recording electrode (Fig. 1D). The hippocampal EEG displayed a regular theta activity during walking and REMS (Fig. $1 E, F)$. Forty-four rats that showed stable responses across experiments were used for data analysis. The average fEPSP threshold intensity for a single-pulse response was $47 \pm 3 \mu \mathrm{A}$, and the average tetanic stimulus intensity was $45 \pm 2 \mu \mathrm{A}$; these stimulus intensities were not significant different across experiment groups (one-way ANOVA).

The results below were presented for the negative fEPSP at the stratum oriens electrode, which was directly generated by the basal-dendritic excitatory sink in CA1 (Leung and Peloquin, 2010). Because the basal-dendritic fEPSP manifests a dipole field, similar results on LTP were found for the stratum radiatum electrode (supplemental Fig. 1, available at www.jneurosci. org as supplemental material).

\section{Effects of TMN histaminergic lesion on CA1 basal-dendritic LTP}

To explore the contribution of physiological histaminergic projection on hippocampal synaptic plasticity, histaminergic neurons were lesioned by bilateral infusions of orexin-saporin in the TMN and subsequently verified by ADA immunostaining after recording experiments were completed. Cell counting in coronal sections through the TMN revealed that the number of ADA-immunoreactive neurons in orexin-saporin lesion rats was

(1:500; Millipore Bioscience Research Reagents) for $2 \mathrm{~d}$ at $4^{\circ} \mathrm{C}$, followed by incubation with biotin-conjugated secondary antibody (1:200; Millipore Bioscience Research Reagents) at room temperature for $1 \mathrm{~h}$. The sections were then placed in the peroxidase-avidin-biotin complex for $1 \mathrm{~h}$ (1:100, Vectastain; Vector Laboratories), and the reaction product was visualized by the diaminobenzidine method.

The number of ADA-immunoreactive cells in TMN was counted in three standardized coronal sections and averaged to yield a single mean for each rat. The three sections were selected based on the morphology of the structures, in particular the shape of the third ventricle, and corresponded approximately to P3.8, P4.16, and P4.3 of the atlas of Paxinos and Watson (1998). The electrode placements and the sites of cannula infusion were verified histologically in $60 \mu \mathrm{m}$ frozen sections of the brain stained with thionin (Fig. $1 A-C$ ).

Statistical analysis. All data are expressed as mean \pm SEM. Statistical differences in the expression of ADA-positive cells between sham and orexin-saporin lesioned animals were analyzed using the unpaired Stu- greatly reduced by $70 \%$ compared with sham control rats $(40 \pm 8$ cells per rat in nine orexin-saporin lesion rats and $132 \pm 10$ cells per rat in eight sham lesion control rats; $p<0.0001$ ) (Fig. 2).

Basal-dendritic LTP was quantified by an increase in fEPSP slope from the baseline, and the potentiation exceeded $200 \%$ of the baseline for $>30 \mathrm{~min}$ after tetanic stimulation and lasted for $>3 \mathrm{~h}$. In animals that received sham lesion in the TMN, basal-dendritic LTP in CA1 was dependent on behavioral state, with LTP induced during walking larger than that induced during REMS (Fig. $3 A, C$ ). Repeated-measures ANOVA showed a significant behavioral-state effect $\left(F_{(1,14)}=10.24\right.$; $p=0.0064)$, a significant time effect $\left(F_{(9,126)}=27.40 ; p<\right.$ $0.0001)$, but no significant state $\times$ time interaction $\left(F_{(9,126)}=\right.$ $1.05 ; p=0.40)$. 
TMN lesion rats showed basal-dendritic LTP induced during either walking or REMS. However, distinct from sham lesion rats, the LTP did not depend on the behavioral state of LTP induction (Fig. $3 B, D$ ). Two-way repeated-measures ANOVA confirmed a lack of significant difference between the LTP induced during walking and that induced during $\operatorname{REMS}\left(F_{(1,16)}=0.20 ; p=0.66\right)$, and there was no significant group $\times$ time interaction $\left(F_{(9,144)}=0.61 ; p=0.79\right)$. LTP was not restricted to one stimulus intensity. Input-output curves generated at 1 or $2 \mathrm{~h}$ after tetanus showed that LTP was facilitated when tetanized during walking compared with during REMS in sham lesion rats, but this facilitation was not present in orexin-saporin lesion rats (supplemental Fig. 2, available at www.jneurosci.org as supplemental material). Pearson's correlation coefficient was statistically significant $(p<0.01$ or $p<0.05)$ between the number of ADA-positive neurons and the ratio of LTP during walking to that during REMS at 60 or 120 min after the tetanus (Fig. 4). The correlation was not significant when the sham or orexin-saporin lesion group was analyzed separately.

Both walking and REMS were accompanied by a regular hippocampal theta rhythm. In sham lesion rats, the average peak theta frequency was $7.9 \pm 0.2 \mathrm{~Hz}$ during walking and $7.0 \pm 0.2 \mathrm{~Hz}$ during REMS (peak theta frequency was derived from the EEG power spectrum for a duration of $1 \mathrm{~s}$ immediately preceding the tetanus). In TMN lesion rats, the average peak theta frequency was $7.9 \pm 0.3 \mathrm{~Hz}$ during walking and $7.1 \pm 0.1 \mathrm{~Hz}$ during REMS. Theta peak frequency was significantly higher during walking than during REMS in both sham and lesion rats $(p<$ $0.05)$, but there was no significant difference between sham and lesion rats for the peak theta frequency of a fixed behavioral state (walking or REMS).

Effects of intraseptal histamine receptor antagonist infusion on basal-dendritic LTP during walking

Stimulation of TMN elicited higher histamine release in the medial septal area than the hippocampus (Mochizuki et al., 1994), likely because of the stronger projection of TMN histaminergic fibers to the medial septal area than the hippocampus (Airaksinen and Panula, 1988; Panula et al., 1989). Thus, we examined whether histaminergic transmission in the medial septum was responsible for the facilitation of basal-dendritic LTP during walking, by means of intraseptal infusion of the $\mathrm{H}_{1}$ receptor antagonist triprolidine or the $\mathrm{H}_{2}$ receptor antagonist cimetidine, followed 10 min later by a tetanic stimulation to elicit LTP.

Septal triprolidine or saline infusion had no significant effects on the baseline fEPSPs. However, triprolidine infusion was followed by a smaller LTP induced during walking ( $173 \pm 8 \%$ of the
B
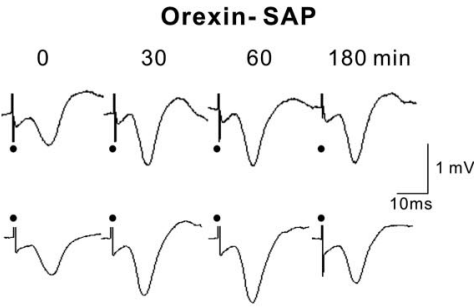

D

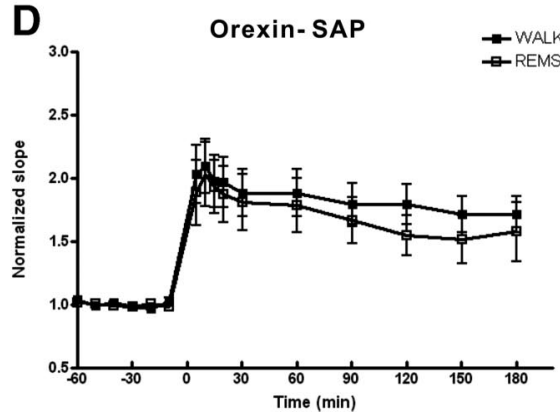

Figure 3. Histaminergic lesion in the tuberomammillary nucleus abolished the difference in hippocampal basal-dendritic LTP 列 of behavioral state (walking vs REMS) on LTP of the sham lesion rat ( $p=0.0064$ ) but not in the orexin-saporin TMN lesion rats

A $60 \mathrm{~min}$

4. Positive correlation between the number of ADA-immunoreactive (ADA-ir) neurons and the ratio of LTP during the number of ADA-immunoreactive neurons and the walk/REMS LTP ratio. Correlation coefficient of $r=0.63$ at $60 \mathrm{~min}$ ( $p=0.007)$ and $r=0.54$ at $120 \mathrm{~min}(p=0.02) ; n=17$ including both orexin-saporin lesion (filled squares) and sham (open squares) rats. baseline at $60 \mathrm{~min}$ ) compared with saline infusion $(208 \pm 14 \%$ at $60 \mathrm{~min}$ ) (Fig. 5A, C). Repeated-measures ANOVA revealed a significant effect of the infused drug $\left(F_{(1,12)}=5.51 ; p<0.05\right)$, a significant time effect $\left(F_{(9,108)}=39.92 ; p<0.0001\right)$, but no significant infusion $\times$ time interaction $\left(F_{(9,108)}=0.52 ; p=0.85\right)$.

Septal cimetidine or saline infusion had no significant effects on the baseline fEPSPs. In addition, there was no significant difference in the LTP induced after cimetidine and saline infusion (infused drug effect, $F_{(1,10)}=0.66, p=0.43$; interaction effect, $\left.F_{(9,90)}=0.61, p=0.78\right)($ Fig. $5 B, D)$.

\section{Effects of intraseptal histamine infusion on} basal-dendritic LTP

The above results suggest that the histaminergic afferents from the TMN to the medial septum were necessary for the facilitation 
A

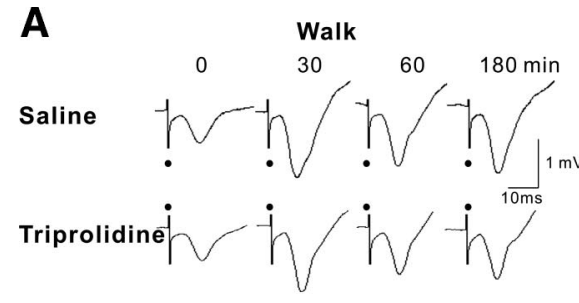

c

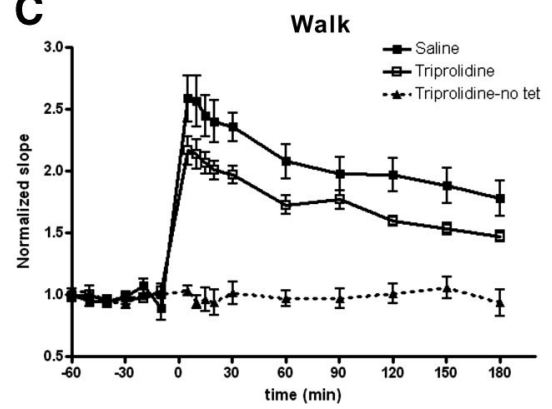

B

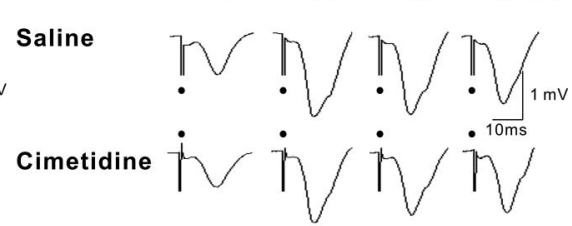

D

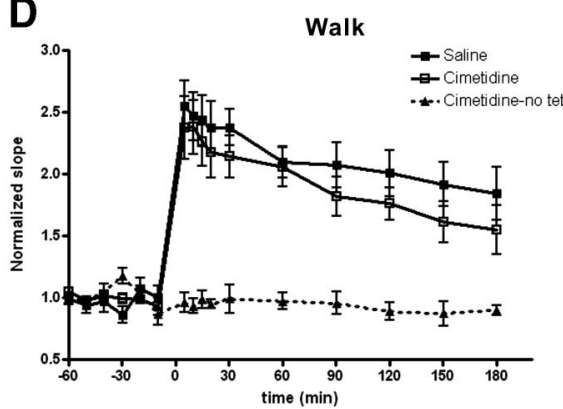

Figure 5. Walking-associated enhancement of LTP was attenuated by intraseptal administration of the $\mathrm{H}_{1}$ histaminergic blocker triprolidine but not the $\mathrm{H}_{2}$ histaminergic blocker cimetidine. $\boldsymbol{A}, \boldsymbol{B}$, Traces of fEPSP at the basal-dendritic electrode of representative rats at 0 (baseline), 30,60, and 180 min after tetanus, with tetanus given during walking at 10 min after intraseptal administration of either triprolidine or saline $(\boldsymbol{A})$ and either cimetidine or saline $(\boldsymbol{B})$. The fEPSPs were scaled to make the peak amplitudes of the baseline response appear identical in $\boldsymbol{A}$ and $\boldsymbol{B}$. C, $\boldsymbol{D}$, Normalized fEPSP slopes (mean \pm SEM), with LTP induced during walking after intraseptal administration of either saline or triprolidine $(\boldsymbol{C})$ and saline or cimetidine $(\boldsymbol{D})$. A two-way (treatment $X$ time) repeated-measures ANOVA revealed a significant effect of triprolidine $(p<0.05)$ but not cimetidine $(p=0.43)$. no-tet, No tetanus.

A

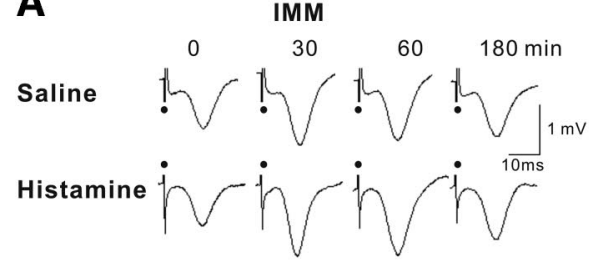

C

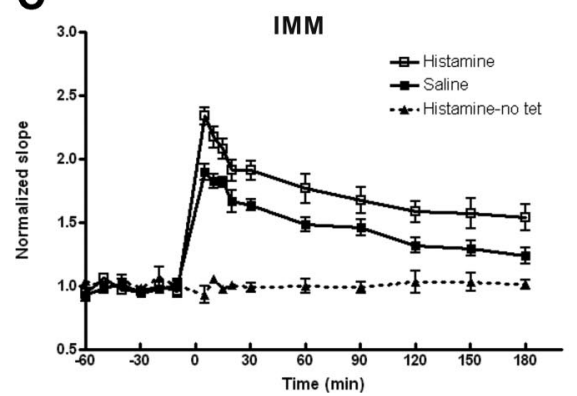

B

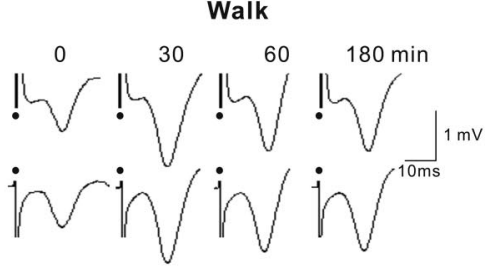

D

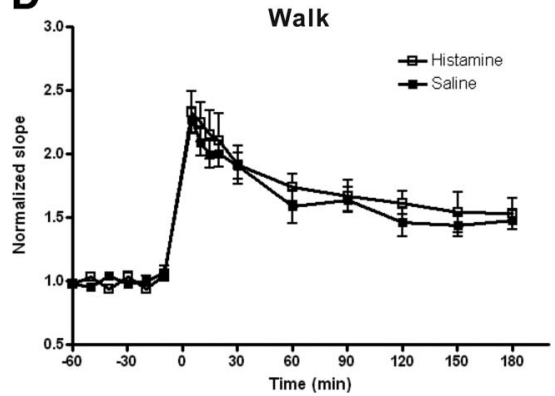

Figure 6. Administration of histamine into the medial septum enhanced LTP induced during IMM but not during walking. $A, B$, fEPSP traces at the basal-dendritic electrode of representative rats at 0 (baseline), 30,60, and $180 \mathrm{~min}$ after tetanus, with tetanus given 10 min after intraseptal administration of either saline or histamine and LTP induced during IMM $(\boldsymbol{A})$ and walking $(\boldsymbol{B})$. The fEPSPs were scaled to make the peak amplitudes of the baseline response appear identical in $\boldsymbol{A}$ and $\boldsymbol{B}$. $\boldsymbol{C}-\boldsymbol{D}$, Normalized fEPSP slopes (mean \pm SEM), with LTP induced after intraseptal administration of either saline or histamine during IMM (C) and walking (D). A two-way (treatment $X$ time) repeated-measures ANOVA revealed a significant effect of histamine versus saline when LTP was induced during IMM ( $p<0.01)$ but not during walking ( $p=0.56)$. no-tet, No tetanus.

of LTP during walking. Because the effect of histamine on in vivo hippocampal LTP has not been demonstrated, we hypothesized that exogenous histamine infused into the medial septal area would facilitate basal-dendritic LTP when the endogenous level of histamine was relatively low, such as during IMM. We also investigated whether basal-dendritic LTP during walking could be further facilitated by septal histamine infusion. Basal-dendritic LTP induced dur- ing REMS was of similar magnitude as that induced during IMM and smaller than that induced during walking (Leung et al., 2003). Because of the difficulty in controlling the time of occurrence of REMS, LTP during REMS was not attempted after histamine administration.

Histamine infusion into the medial septum had no significant effect on the baseline fEPSPs but induced an activating effect on the hippocampal EEG. At 7-10 min after histamine, a decrease in irregular slow waves or an increase in theta rhythm during IMM was found in five of seven rats with available EEG (supplemental Fig. 3, available at www. jneurosci.org as supplemental material). When LTP was induced during IMM, 10 min after histamine or saline infusion in the medial septum, the septal-histamine group showed a larger LTP than the septal-saline group. At $60 \mathrm{~min}$ after tetanus, LTP measured $177 \pm 11 \%$ of the baseline in the histamine-infused group compared with $149 \pm 5 \%$ of the baseline in the salineinfused group (Fig. 6A, C). Repeated-measures ANOVA confirmed a significant main effect of histamine $\left(F_{(1,12)}=12.19 ; p=\right.$ $0.0044)$, a significant time effect $\left(F_{(9,108)}=\right.$ 43.94; $p<0.0001)$, but no significant histamine $\times$ time interaction $\left(F_{(9,108)}=\right.$ $0.69 ; p=0.72$ ).

In another group of rats, LTP was induced during walking after intraseptal saline or histamine infusion. LTP induced during walking was not significantly different between the histamine- and saline-infused groups (Fig. $6 B, D$ ), as shown by the lack of significant main effect $\left(F_{(1,12)}=0.36 ; p=\right.$ $0.56)$ and interaction effect $\left(F_{(9,108)}=0.42\right.$; $p=0.92)$.

\section{Discussion}

This study provides original results that behavior-dependent histaminergic activity enhanced hippocampal LTP in behaving rats. The facilitation of basal-dendritic LTP during walking, compared with REMS, was abolished if TMN neurons were lesioned or when the $\mathrm{H}_{1}$ receptor antagonist triprolidine was infused into the medial septum. When LTP was induced during IMM, histamine infusion into the medial septum enhanced LTP to a degree similar to the LTP induced during walking. Thus, in total, the experiments provide evidence that histaminergic activity in the septum is necessary and sufficient for the facilitation of basaldendritic LTP during walking in the hippocampus.

\section{LTP facilitation by behavior-dependent activity of TMN} histaminergic neurons

The magnitude of LTP induced during walking was greater than that induced during REMS in sham lesion rats, confirming a 
previous report on intact rats (Leung et al., 2003). However, after lesion of the histaminergic neuron by infusing orexin-saporin into the TMN, the facilitation of basal-dendritic LTP induced during walking was abolished, and LTP induced during walking was similar to that induced during REMS. TMN infusion of orexin-saporin may ablate adjacent nonhistaminergic neurons with orexin-2 receptors, and whether this has an effect on hippocampal LTP remains to be studied. We showed that the number of ADA-immunoreactive cells, a marker of histaminergic neurons in the hypothalamus except for the posterior arcuate nucleus (Senba et al., 1985), was greatly reduced by orexin-saporin infusion. The number of ADA-immunoreactive cells correlated significantly with the walking-LTP to REMS-LTP ratio, suggesting that histaminergic neurons in TMN are necessary for the facilitation of LTP induced during walking. Histaminergic neuronal activity is suggested to provide the additional activation factor that is necessary for LTP facilitation during walking compared with REMS. Activity of histaminergic neurons is high during active awake and low during REMS (Takahashi et al., 2006), whereas cholinergic activity in the hippocampus is similarly high during walking and REMS (Vanderwolf, 1988; Marrosu et al., 1995).

Hippocampal LTP is needed for the formation of place fields (Muller et al., 1996; Dragoi et al., 2003; Isaac et al., 2009). A spatial map, presumably constructed from hippocampal neurons with different place fields, is established when an animal actively moved, but not when passively carried, through an environment (O'Keefe and Nadel, 1978; Foster et al., 1989). We showed that an increase in histaminergic and cholinergic activity during walking enhanced hippocampal LTP, which would facilitate construction of a spatial map. Muscarinic blockade weakened the locationspecific firing of place cells (Brazhnik et al., 2003), and, based on the present results, similar results may be expected after histaminergic blockade in the medial septum.

\section{LTP and histamine}

We found that histamine administration into medial septum facilitated basal-dendritic LTP if the LTP was induced during IMM but not if it was induced during walking. LTP induced during walking was not affected by exogenous histamine administration in the medial septum, possibly because the level of histamine released endogenously was already high (Takahashi et al., 2006) such that an additional LTP enhancement may not occur. In contrast, histamine release during IMM is expected to be low, and histamine administration in the medial septum was found to facilitate the LTP induced during IMM.

We showed that histamine action on the medial septum was sufficient to facilitate basal-dendritic LTP during IMM, and $\mathrm{H}_{1}$ but not $\mathrm{H}_{2}$ receptor blockade in the medial septum suppressed the facilitation of basal-dendritic LTP during walking. There have been very few studies of histaminergic effects on hippocampal LTP in vivo. Intracerebroventricular injection of cimetidine was reported to inhibit the induction of LTP of the perforant path to dentate gyrus in urethane-anesthetized rats but presumably not by means of $\mathrm{H}_{2}$ receptor blockade (Chang et al., 1997).

Our results showed a definitive role of histamine on the medial septum but did not exclude a direct action of histamine on the hippocampus in vivo. In hippocampal slices (isolated from the medial septum) in vitro, direct application of histamine enhanced hippocampal LTP (Brown et al., 1995). Histamine has been shown to enhance hippocampal NMDA receptor currents (Bekkers, 1993; Vorobjev et al., 1993; Brown et al., 1995). LTP of the Schaffer collateral (presumed apical dendritic) synapses in
CA1 in vitro was reduced in $\mathrm{H}_{1}$ and $\mathrm{H}_{2}$ receptor gene knock-out mice (Dai et al., 2007), but potentiation of population spikes was enhanced in mice lacking histidine decarboxylase, the enzyme responsible for the synthesis of histamine (Liu et al., 2007).

\section{Medial septum mediates histaminergic regulation of hippocampal synaptic plasticity}

Histamine administration in the medial septum decreased the low-frequency power of the hippocampal EEG during IMM, occasionally accompanied by a theta rhythm. The histamineinduced effects were similar to those accompanying EEG activation induced by anticholinesterase physostigmine (Leung, 1985; Doralp and Leung, 2008). A decrease in $200 \mathrm{~Hz}$ ripples, another indicator of hippocampal EEG activation, was observed after intracerebroventricular injection of histamine (Knoche et al., 2003). The activation of hippocampal EEG was likely caused by ACh release in the hippocampus after application of histamine in the medial septum (Bacciottini et al., 2002). Histamine depletion blocked the TMN-stimulated release of histamine from the septal area and ACh release from the hippocampus (Mochizuki et al., 1994). $H_{1}$ receptors were reported to mediate the histamineinduced depolarization of septal cholinergic neurons in vitro (Gorelova and Reiner, 1996; Xu et al., 2004), although $\mathrm{H}_{2}$ receptor activation was reported to be necessary for spontaneous release of ACh, collected in $20 \mathrm{~min}$ samples, in the hippocampus in vivo (Bacciottini et al., 2002). The type of histaminergic receptors involved in behavior-dependent release of Ach is not known.

The present results show that the medial septum is a key anatomical site involved in modulating hippocampal LTP by histamine. The medial septum comprises a heterogeneous population of neurons, including cholinergic, GABAergic, and glutamatergic neurons, that project to the hippocampus (Brashear et al., 1986; Freund and Antal, 1988; Sotty et al., 2003; Colom et al., 2005). Combined with our previous demonstration that selective lesion of cholinergic neurons in the medial septum with 192IgG-saporin also abolished the facilitation of LTP by walking (Leung et al., 2003), the most parsimonious model consistent with the literature is that histamine excites cholinergic septohippocampal neurons to increase ACh release in the hippocampus. ACh, in turn, may facilitate basal-dendritic LTP by increasing spiking after basal-dendritic excitation (Leung and Peloquin, 2010) or by enhancing NMDA receptor-mediated current (Markram and Segal, 1992; Marino et al., 1998).

Acetylcholine release by septohippocampal neurons alone cannot explain the difference of LTP between walking and REMS, and participation of septohippocampal GABAergic and glutamatergic neurons is likely. Histamine excites septohippocampal GABAergic neurons via both direct and indirect mechanisms (Xu et al., 2004). The indirect mechanism involves activation of muscarinic $\mathrm{M}_{3}$ receptors by locally released ACh subsequent to an $\mathrm{H}_{1}$ receptor-mediated activation of septohippocampal cholinergic neurons (Xu et al., 2004). Septohippocampal GABAergic neurons may then facilitate hippocampal LTP by disinhibiting hippocampal pyramidal cells (Tóth et al., 1997). The high activity of GABAergic neurons across all vigilance states (Simon et al., 2006) may provide a strong modulation of hippocampal activity. However, basal forebrain GABAergic neuronal firing was not generally different between active waking and REMS (Simon et al., 2006; Hassani et al., 2009). In contrast, a group of putative glutamatergic neurons in the basal forebrain (substantia innominata) fired maximally during active waking and minimally during REMS (Hassani et al., 2009). The latter glutamatergic neurons would provide behaviorally dependent modulation of hip- 
pocampal LTP, but whether they are differentially modulated by histamine during active waking is not known.

In summary, this study provides original results that histaminergic activity is both necessary and sufficient for the facilitation of basal-dendritic LTP in hippocampal CA1 of behaving animals. The mechanism likely involves activation of $\mathrm{H}_{1}$ receptors on septohippocampal neurons by histamine released from TMN afferents.

\section{References}

Airaksinen MS, Panula P (1988) The histaminergic system in the guinea pig central nervous system: an immunocytochemical mapping study using an antiserum against histamine. J Comp Neurol 273:163-186.

Aston-Jones G, Bloom FE (1981) Activity of norepinephrine-containing locus coeruleus neurons in behaving rats anticipates fluctuations in the sleep-waking cycle. J Neurosci 1:876-886.

Bacciottini L, Passani MB, Giovannelli L, Cangioli I, Mannaioni PF, Schunack W, Blandina P (2002) Endogenous histamine in the medial septumdiagonal band complex increases the release of acetylcholine from the hippocampus: a dual-probe microdialysis study in the freely moving rat. Eur J Neurosci 15:1669-1680.

Bekkers JM (1993) Enhancement by histamine of NMDA-mediated synaptic transmission in the hippocampus. Science 261:104-106.

Blanco-Centurion C, Gerashchenko D, Shiromani PJ (2007) Effects of saporin-induced lesions of three arousal populations on daily levels of sleep and wake. J Neurosci 27:14041-14048.

Brashear HR, Zaborszky L, Heimer L (1986) Distribution of GABAergic and cholinergic neurons in the rat diagonal band. Neuroscience 17:439-451.

Brazhnik ES, Muller RU, Fox SE (2003) Muscarinic blockade slows and degrades the location-specific firing of hippocampal pyramidal cells. J Neurosci 23:611-621.

Brown RE, Fedorov NB, Haas HL, Reymann KG (1995) Histaminergic modulation of synaptic plasticity in area CA1 of rat hippocampal slices. Neuropharmacology 34:181-190.

Cecchi M, Passani MB, Bacciottini L, Mannaioni PF, Blandina P (2001) Cortical acetylcholine release elicited by stimulation of histamine $\mathrm{H} 1 \mathrm{re}-$ ceptors in the nucleus basalis magnocellularis: a dual-probe microdialysis study in the freely moving rat. Eur J Neurosci 13:68-78.

Chang M, Saito H, Abe K (1997) Cimetidine inhibits the induction of longterm potentiation in the dentate gyrus of rats in vivo. Jpn J Pharmacol 74:281-283.

Colom LV, Castaneda MT, Reyna T, Hernandez S, Garrido-Sanabria E (2005) Characterization of medial septal glutamatergic neurons and their projection to the hippocampus. Synapse 58:151-164.

Dai H, Kaneko K, Kato H, Fujii S, Jing Y, Xu A, Sakurai E, Kato M, Okamura N, Kuramasu A, Yanai K (2007) Selective cognitive dysfunction in mice lacking histamine $\mathrm{H} 1$ and $\mathrm{H} 2$ receptors. Neurosci Res 57:306-313.

Dere E, De Souza-Silva MA, Topic B, Spieler RE, Haas HL, Huston JP (2003) Histidine-decarboxylase knockout mice show deficient nonreinforced episodic object memory, improved negatively reinforced water-maze performance, and increased neo- and ventro-striatal dopamine turnover. Learn Mem 10:510-519.

Doi T, Sakata T, Yoshimatsu H, Machidori H, Kurokawa M, Jayasekara LA, Niki N (1994) Hypothalamic neuronal histamine regulates feeding circadian rhythm in rats. Brain Res 641:311-318.

Doralp S, Leung LS (2008) Cholinergic modulation of hippocampal CA1 basal-dendritic long-term potentiation. Neurobiol Learn Mem 90:382-388.

Dragoi G, Harris KD, Buzsáki G (2003) Place representation within hippocampal networks is modified by long-term potentiation. Neuron 39:843-853.

Dudar JD, Whishaw IQ, Szerb JC (1979) Release of acetylcholine from the hippocampus of freely moving rats during sensory stimulation and running. Neuropharmacology 18:673-678.

Eriksson KS, Sergeeva O, Brown RE, Haas HL (2001) Orexin/hypocretin excites the histaminergic neurons of the tuberomammillary nucleus. J Neurosci 21:9273-9279.

Fornal C, Auerbach S, Jacobs BL (1985) Activity of serotonin-containing neurons in nucleus raphe magnus in freely moving cats. Exp Neurol 88:590-608.

Foster TC, Castro CA, McNaughton BL (1989) Spatial selectivity of rat hip- pocampal neurons: dependence on preparedness for movement. Science 244:1580-1582.

Freund TF, Antal M (1988) GABA-containing neurons in the septum control inhibitory interneurons in the hippocampus. Nature 336:170-173.

Gerashchenko D, Chou TC, Blanco-Centurion CA, Saper CB, Shiromani PJ (2004) Effects of lesions of the histaminergic tuberomammillary nucleus on spontaneous sleep in rats. Sleep 27:1275-1281.

Gorelova N, Reiner PB (1996) Histamine depolarizes cholinergic septal neurons. J Neurophysiol 75:707-714.

Haas H, Panula P (2003) The role of histamine and the tuberomamillary nucleus in the nervous system. Nat Rev Neurosci 4:121-130.

Haas HL, Sergeeva OA, Selbach O (2008) Histamine in the nervous system. Physiol Rev 88:1183-1241.

Hassani OK, Lee MG, Henny P, Jones BE (2009) Discharge profiles of identified GABAergic in comparison to cholinergic and putative glutamatergic basal forebrain neurons across the sleep-wake cycle. J Neurosci 29:11828-11840.

Inoue I, Yanai K, Kitamura D, Taniuchi I, Kobayashi T, Niimura K, Watanabe T, Watanabe T (1996) Impaired locomotor activity and exploratory behavior in mice lacking histamine $\mathrm{H} 1$ receptors. Proc Natl Acad Sci U S A 93:13316-13320.

Isaac JT, Buchanan KA, Muller RU, Mellor JR (2009) Hippocampal place cell firing patterns can induce long-term synaptic plasticity in vitro. J Neurosci 29:6840-6850.

Knoche A, Yokoyama H, Ponomarenko A, Frisch C, Huston J, Haas HL (2003) High-frequency oscillation in the hippocampus of the behaving rat and its modulation by the histaminergic system. Hippocampus 13:273-280.

Kuo MC, Dringenberg HC (2008) Histamine facilitates in vivo thalamocortical long-term potentiation in the mature visual cortex of anesthetized rats. Eur J Neurosci 27:1731-1738.

Lee MG, Hassani OK, Alonso A, Jones BE (2005) Cholinergic basal forebrain neurons burst with theta during waking and paradoxical sleep. J Neurosci 25:4365-4369.

Leung LS, Peloquin P (2010) Cholinergic modulation differs between basal and apical dendritic excitation of hippocampal CA1 pyramidal cells. Cereb Cortex. Advance online publication. Retrieved November 19, 2009. doi:10.1093/cercor/bhp251.

Leung LS, Shen B (1993) Long-term potentiation in hippocampal CA1: effects of afterdischarges, NMDA antagonists, and anticonvulsants. Exp Neurol 119:205-214.

Leung LS, Shen B (1995) Long-term potentiation at the apical and basal dendritic synapses of CAl after local stimulation in behaving rats. J Neurophysiol 73:1938-1946.

Leung LS, Shen B (1999) N-methyl-D-aspartate receptor antagonists are less effective in blocking long-term potentiation at apical than basal dendrites in hippocampal CA1 of awake rats. Hippocampus 9:617-630.

Leung LS, Shen B, Rajakumar N, Ma J (2003) Cholinergic activity enhances hippocampal long-term potentiation in CA1 during walking in rats. J Neurosci 23:9297-9304.

Leung LW (1985) Spectral analysis of hippocampal EEG in the freely moving rat: effects of centrally active drugs and relations to evoked potentials. Electroencephalogr Clin Neurophysiol 60:65-77.

Liu L, Zhang S, Zhu Y, Fu Q, Zhu Y, Gong Y, Ohtsu H, Luo J, Wei E, Chen Z (2007) Improved learning and memory of contextual fear conditioning and hippocampal CA1 long-term potentiation in histidine decarboxylase knock-out mice. Hippocampus 17:634-641.

Marino MJ, Rouse ST, Levey AI, Potter LT, Conn PJ (1998) Activation of the genetically defined m1 muscarinic receptor potentiates $N$-methyl-Daspartate (NMDA) receptor currents in hippocampal pyramidal cells. Proc Natl Acad Sci U S A 95:11465-11470.

Markram H, Segal M (1992) The inositol 1,4,5-trisphosphate pathway mediates cholinergic potentiation of rat hippocampal neuronal responses to NMDA. J Physiol 447:513-533.

Marrosu F, Portas C, Mascia MS, Casu MA, Fà M, Giagheddu M, Imperato A, Gessa GL (1995) Microdialysis measurement of cortical and hippocampal acetylcholine release during sleep-wake cycle in freely moving cats. Brain Res 671:329-332.

Martin SJ, Grimwood PD, Morris RG (2000) Synaptic plasticity and memory: an evaluation of the hypothesis. Annu Rev Neurosci 23:649-711.

Mochizuki T, Okakura-Mochizuki K, Horii A, Yamamoto Y, Yamatodani A 
(1994) Histaminergic modulation of hippocampal acetylcholine release in vivo. J Neurochem 62:2275-2282.

Muller RU, Stead M, Pach J (1996) The hippocampus as a cognitive graph. J Gen Physiol 107:663-694.

Neves G, Cooke SF, Bliss TV (2008) Synaptic plasticity, memory and the hippocampus: a neural network approach to causality. Nat Rev Neurosci 9:65-75.

O’Keefe J, Nadel L (1978) Hippocampus as a cognitive map. London: Oxford UP.

Panula P, Pirvola U, Auvinen S, Airaksinen MS (1989) Histamineimmunoreactive nerve fibers in the rat brain. Neuroscience 28:585-610.

Parmentier R, Ohtsu H, Djebbara-Hannas Z, Valatx JL, Watanabe T, Lin JS (2002) Anatomical, physiological, and pharmacological characteristics of histidine decarboxylase knock-out mice: evidence for the role of brain histamine in behavioral and sleep-wake control. J Neurosci 22:76957711.

Paxinos G, Watson C (1998) The rat brain in stereotaxic coordinates. San Diego: Academic.

Senba E, Daddona PE, Watanabe T, Wu JY, Nagy JI (1985) Coexistence of adenosine deaminase, histidine decarboxylase, and glutamate decarboxylase in hypothalamic neurons of the rat. J Neurosci 5:3393-3402.

Sherin JE, Elmquist JK, Torrealba F, Saper CB (1998) Innervation of histaminergic tuberomammillary neurons by GABAergic and galaninergic neurons in the ventrolateral preoptic nucleus of the rat. J Neurosci 18:4705-4721.

Simon AP, Poindessous-Jazat F, Dutar P, Epelbaum J, Bassant MH (2006) Firing properties of anatomically identified neurons in the medial septum of anesthetized and unanesthetized restrained rats. J Neurosci 26:9038-9046.

Sotty F, Danik M, Manseau F, Laplante F, Quirion R, Williams S (2003) Distinct electrophysiological properties of glutamatergic, cholinergic and GABAergic rat septohippocampal neurons: novel implications for hippocampal rhythmicity. J Physiol 551:927-943.

Takahashi K, Lin JS, Sakai K (2006) Neuronal activity of histaminergic tuberomammillary neurons during wake-sleep states in the mouse. J Neurosci 26:10292-10298.

Tóth K, Freund TF, Miles R (1997) Disinhibition of rat hippocampal pyramidal cells by GABAergic afferents from the septum. J Physiol 500: 463-474.

Vanderwolf CH (1988) Cerebral activity and behavior: control by central cholinergic and serotonergic systems. Int Rev Neurobiol 30:225-340.

Vorobjev VS, Sharonova IN, Walsh IB, Haas HL (1993) Histamine potentiates $N$-methyl-D-aspartate responses in acutely isolated hippocampal neurons. Neuron 11:837-844.

Xu C, Michelsen KA, Wu M, Morozova E, Panula P, Alreja M (2004) Histamine innervation and activation of septohippocampal GABAergic neurones: involvement of local ACh release. J Physiol 561:657-670. 